\title{
Thyroid Surgeries Under Bilateral Superficial Cervical Plexus Block - A Case Series
}

\author{
Satish V Kamat ${ }^{1}$, Prabhakar Subramanian ${ }^{2}$, Kala Eswaran ${ }^{3}$
}

\section{Abstract}

Superficial cervical plexus block is a simple regional anesthesia procedure which can be performed by landmark guided as well as ultrasoundguided techniques. It has been used to provide anesthesia or analgesia for various procedures involving superficial surgeries in the neck and shoulder. The pain after thyroid surgery is of mild to moderate intensity and of short duration. I describe 12 cases in which bilateral superficial cervical plexus block was performed to conduct awake thyroid surgeries.

Keywords: thyroid surgery, superficial cervical plexus block, regional anesthesia, neck surgeries, analgesia

\section{Introduction}

The anesthesia technique for thyroid surgery depends on the complexity of the procedure. It may vary from a simple nodule excision to the removal of a large gland with retrosternal extension [1]. Patients undergoing thyroid surgery experience mild to moderate post-operative pain in the first 24 hours [2]. Besides general anesthesia, it can also be performed under loco-regional anesthesia whenever feasible. Regional anesthesia (RA) provides site-specific anesthesia or analgesia with minimal systemic effects. In the past, thyroid surgeries were performed under local anesthesia [3]. It has also been reported with superficial cervical plexus block (SCPB), Deep cervical plexus block (DCPB), and cervical epidural anesthesia (CEA) as sole anesthesia technique with or without sedation $[3,4,5]$. SCPB can be performed by anatomical landmark guided and ultrasound-guided techniques. Anaesthesiologists without any access to an ultrasound machine or training in ultrasound-guided RA can also perform this simple block with just a needle and syringe filled with local anaesthetics.

Anatomical landmark guided SCPB was performed in twelve patients for various thyroid surgeries. The author describes her technique to facilitate awake thyroid surgeries in terms of optimal perioperative analgesia, intraoperative hemodynamic stability, and decrease airway manipulation.

\section{Case Report}

The anesthesia plan was discussed with the patient and surgeons and written informed consent was taken from each patient during pre-anesthetic check-up (PAC). Consent for perioperative collection of data and possible publication were also taken. All details were collected by using a mobile app Regional Anesthesia Database (RAD v1.4.1.24, Medusys) [6]. The data recorded included age, gender, weight, height, Comorbid conditions and American Society of Anaesthesiologists physical status (ASA) of the patient, diagnosis, surgical procedure being performed, dimensions of the thyroid gland from ultrasonography report, duration of surgery, medications used for sedation, duration of analgesia, dose of rescue analgesic needed in first 24 hours, any complications, days spent in high dependency unit /intensive care unit(HDU/ICU) and total duration of hospital stay following surgery (Table 1,2).

On the day of surgery, an intravenous line was secured and standard monitors were attached. Landmark guided bilateral SCPB was performed in all patients in the supine position. LA was injected at the mid-portion of the posterior border of the sternocleidomastoid muscle (SCM) in a 'fan-shaped' manner without piercing the fascia (figure 1). The branches of the superficial cervical plexus emerge from behind the posterior border of the SCM muscle. $10 \mathrm{cc}$ of LA solution ( 5 cc $2 \%$ lignocaine-adrenaline and 5 cc $0.75 \%$ ropivacaine) was

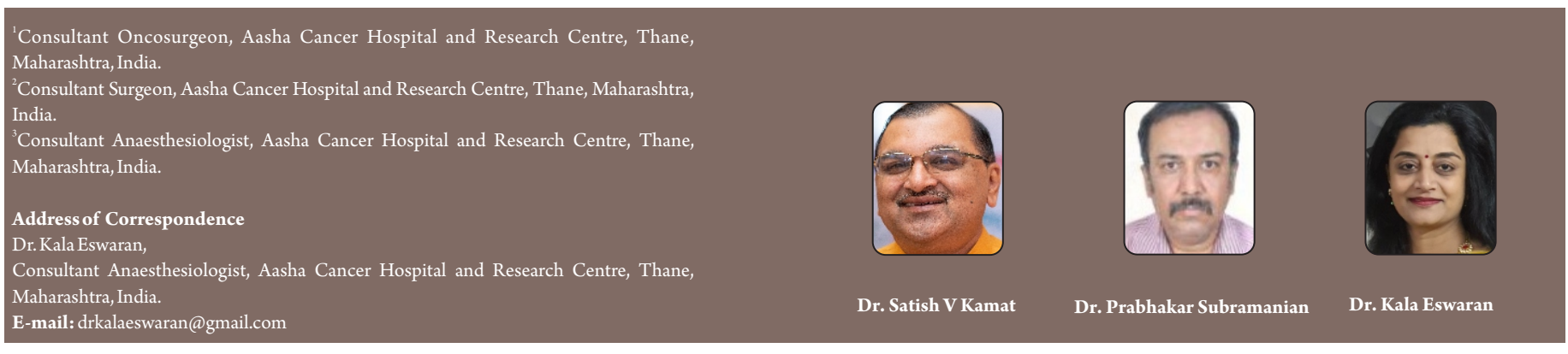

Submitted: 24 March 2020; Reviewed: 12 May 2020; Accepted: 30 December 2020; Published: 10 May 2021

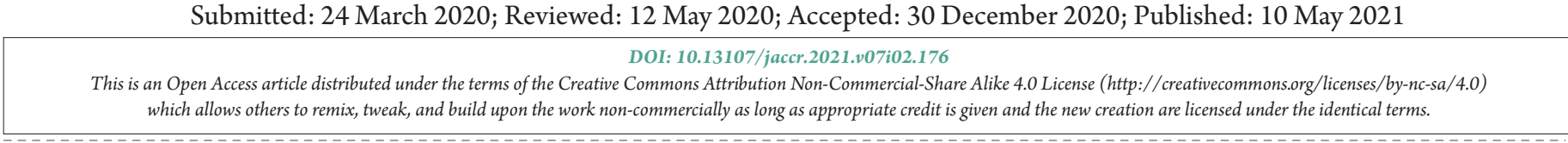




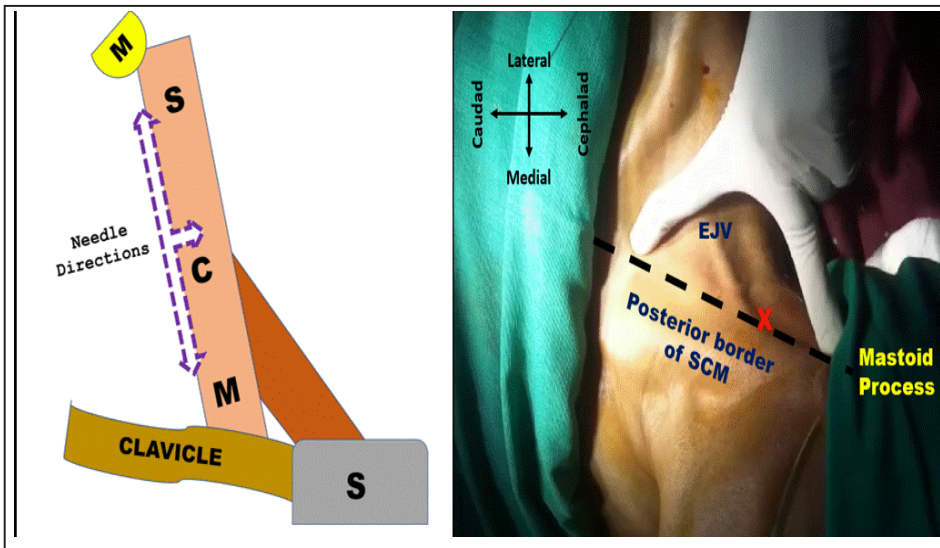

Figure 1: Superficial Cervical Plexus block; $\mathrm{SCM}=$ Sternocleidomastoid, $\mathrm{M}=$ mastoid process, $\mathrm{S}=$ sternum, purple dotted lines= needle directions, EJV= External Jugular Vein, Red ' $\mathrm{x}$ ' = point of needle insertion

\begin{tabular}{|c|c|c|c|c|c|c|c|c|c|}
\hline Case & $\begin{array}{l}\text { Age } \\
\& \\
\text { Sex }\end{array}$ & ASA PS & $\begin{array}{l}\text { Co-morbid } \\
\text { conditions }\end{array}$ & $\begin{array}{l}\text { Weight } \\
(\mathrm{kg})\end{array}$ & $\begin{array}{c}\text { Height } \\
(\mathrm{cm})\end{array}$ & Diagnosis & $\begin{array}{l}\text { Dimensions of thyroid } \\
\text { gland }\left(\mathrm{cm}^{3}\right)\end{array}$ & Surgery & $\begin{array}{c}\text { Duration o } \\
\text { surgery } \\
\text { (min) }\end{array}$ \\
\hline 1 & $57 / \mathrm{M}$ & II & DM HTn & 82 & 170 & Ca Thyroid & $2.7 \times 1.2 \times 2.8$ & RH & 40 \\
\hline 2 & $62 / F$ & II & $\begin{array}{l}\text { HOCM with } \\
\text { moderate AS }\end{array}$ & 67 & 162 & MNG & $3 \times 1.5 \times 2.5$ & RH & 45 \\
\hline 3 & $48 / \mathrm{F}$ & II & Epilepsy & 63 & 157 & Ca Thyroid & $3 \times 2.8 \times 4$ & ST & 75 \\
\hline 4 & $68 / \mathrm{F}$ & III & $\begin{array}{r}\text { Severe COPD Low } \\
\text { lung reserves in PFT }\end{array}$ & 51 & 162 & Ca Thyroid & $10 \times 8 \times 6$ & NT & 120 \\
\hline 5 & $72 / F$ & III & $\begin{array}{c}\text { DM, IHD with LVEF } \\
30 \%\end{array}$ & 80 & 155 & MNG & $6 \times 5 \times 8$ & LH & 130 \\
\hline 6 & $45 / \mathrm{M}$ & II & DM, BA & 66 & 172 & Goitre & $4 \times 4.1 \times 3.7$ & RH & 90 \\
\hline 7 & $82 / F$ & III & COPD, HTn & 76 & 160 & Ca Thyroid & $3.8 \times 5 \times 2.7$ & ST & 150 \\
\hline 8 & $55 / \mathrm{M}$ & III & $\begin{array}{c}\text { IHD with LVEF } 30 \% \\
\text { DM }\end{array}$ & 72 & 172 & Goitre & $6 \times 4 \times 8$ & LH & 90 \\
\hline 9 & $37 / M$ & I & - & 72 & 170 & MNG & $2 \times 0.5 \times 1.8$ & $\mathrm{RH}$ & 30 \\
\hline 10 & $47 / \mathrm{M}$ & III & $\begin{array}{c}\text { BA, DM Post } \\
\text { Angioplasty status }\end{array}$ & 78 & 172 & MNG & $5 \times 6 \times 6$ & ST & 50 \\
\hline 11 & $80 / \mathrm{M}$ & III & COPD Bronchiectasis & 68 & 170 & MNG & $8 \times 5 \times 6$ & LH & 60 \\
\hline 12 & $55 / \mathrm{f}$ & I & - & 75 & 175 & Ca Thyroid & $5 \times 4 \times 8$ & RH & 75 \\
\hline \multicolumn{10}{|c|}{$\begin{array}{l}\text { ASA PS = American Society of Anesthesiologist Physical Status, M = Male, F = Female, RH= Right Hemithyroidectomy, } \\
\text { LH= Left hemithyroidectomy, ST= Subtotal thyroidectomy, NT= Near Total thyroidectomy, MNG= Multinodular goitre, } \\
\text { DM = Diabetes Mellitus, BA= Bronchial Asthma, HTn = Hypertension, IHD= Ischaemic heart disease, LVEF = left } \\
\text { ventricular ejection fraction, COPD = Chronic Obstructive Pulmonary Disease, HOCM = Hypertrophic Obstructive } \\
\text { Cardiomyopathy, AS = Aortic Stenosis, Ca = Carcinoma }\end{array}$} \\
\hline
\end{tabular}

used for SCPB on each side after negative aspiration for blood. The block was assessed by spirit-soaked cotton and blunt tip needle in the desired dermatomes. Intravenous midazolam, fentanyl, pentazocine, and dexmedetomidine were used for anxiolysis and sedation depending on the associated comorbidities (Table 1,2). All patients received 1 gm of paracetamol, $75 \mathrm{mg}$ diclofenac, $8 \mathrm{mg}$ dexamethasone, and $4 \mathrm{mg}$ ondansetron intraoperatively. Patients' heart rate, 3-lead ECG, et $\mathrm{CO}_{2}$, and $\mathrm{SpO}_{2}$ were monitored continuously. All patients received $\mathrm{O}_{2}$ inhalation by nasal prong at a rate of 2-3 lit/min. Postoperatively, all patients received $1 \mathrm{gm}$ paracetamol $6^{\text {th }}$ hourly and diclofenac $75 \mathrm{mg} 12^{\text {th }}$ hourly. Intravenous tramadol $100 \mathrm{mg} 8^{\text {th }}$ hourly was used in 3 patients instead of diclofenac (case 4, 7 and 11)(Table 1). None of the patients required intravenous fentanyl bolus as rescue analgesia in the first 24 hours. Duration of surgery was recorded from incision to removal of the specimen because the skin closure was often done by resident physicians, with varying closure times.
All patients successfully underwent awake thyroidectomy under RA and monitored anesthesia care(MAC). One patient developed intra operative airway obstruction due to tongue fall which was managed by placement of a nasopharyngeal airway. Another patient with carcinoma thyroid developed change in voice following surgery due to recurrent laryngeal nerve palsy. Following surgery, high-risk patients were kept in ICU/HDU for observation and were discharged within 3 days.

\section{Discussion}

SCPB provides effective anesthesia and/or analgesia for the head and neck surgeries. It was described as a subcutaneous injection or field block targeting superficial branches of the cervical plexus [7]. The cervical plexus is formed by the ventral rami of the upper four cervical (C1-C4) nerves. The superficial branches of the plexus innervate the skin and superficial structures of the head, neck, and shoulder. The deep branches innervate the muscles of the deep anterior neck and the diaphragm. The superficial branches of the cervical plexus can be divided as follows: ascending branches (Lesser occipital, C2 and Greater auricular, C2, C3; transverse branch(Transverse/anterior cutaneous nerve of the neck, C2, C3) and descending branches (Supraclavicular, C3, C4) [8]. The plexus is resting on the levator scapulae and scalenus medius muscles and is covered by the SCM.

SCPB is easy to perform and reproducible because of its superficial landmark. It is safer than DCPB and CEA, maintains intraoperative hemodynamic stability, avoids risks of GA and its complications, helps in early mobilization, and less stay in hospital or intensive care unit. Various combinations of SCPB with general anesthesia or DCPB have been tried for thyroid surgeries. Bilateral SCPB has shown to reduce intraoperative requirement of general anesthetics during thyroidectomy, lowers the severity of postoperative pain during the first 24 hours, and shortens the hospital stay [9]. Deeper structures of the neck may not be covered by SCPB which can't alleviate pain on swallowing. According to literature, $\mathrm{SCPB}$ has similar results as compared to the combination of SCPB and DCPB. So, SCPB is probably sufficient for thyroid surgeries in selective cases. I did not use DCPB because of the higher rate of serious complications like accidental injection of LA into the vertebral artery, inadvertent spread into subarachnoid or epidural space, and unintended blockade of the vagus nerve, brachial plexus or phrenic nerve [7]. Phrenic nerve palsy is not a problem for healthy individuals but may not be desirable in patients with compromised lung function.

Awake thyroid surgery is valid, safe, and well-tolerated procedure in selective cases [10]. Patient selection is most important to avoid intraoperative conversion to GA. Each

18 | Journal of Anaesthesia and Critical Care Case Reports | Volume 7 | Issue 2 | May-August 2021 | Page 17-20 


\begin{tabular}{|c|c|c|c|c|c|c|}
\hline Case & i.v. sedation & $\begin{array}{l}\text { Duration of } \\
\text { analgesia } \\
\text { (hrs) }\end{array}$ & $\begin{array}{l}\text { Requirement of } \\
\text { rescue } \\
\text { analgesic in } \\
\text { first } 24 \text { hours }\end{array}$ & Complications & $\begin{array}{c}\text { ICU/HDU } \\
\text { stay(days) }\end{array}$ & $\begin{array}{l}\text { Total duration of } \\
\text { hospital stays } \\
\text { following } \\
\text { surgery(days) }\end{array}$ \\
\hline 1 & $\begin{array}{l}\text { Midazolam }-2 \mathrm{mg} \\
\text { Fentanyl }-50 \mathrm{mcg}\end{array}$ & 24 & - & - & - & 2 \\
\hline 2 & $\begin{array}{l}\text { Midazolam }-2 \mathrm{mg} \\
\text { Pentazocine } 30 \mathrm{mg}\end{array}$ & 28 & - & - & - & 1 \\
\hline 3 & $\begin{array}{l}\text { Midazolam }-2 \mathrm{mg} \\
\text { Pentazocine } 30 \mathrm{mg}\end{array}$ & 30 & - & - & - & 3 \\
\hline 4 & $\begin{array}{l}\text { Midazolam }-2 \mathrm{mg} \\
\text { Fentanyl }-50 \mathrm{mcg}\end{array}$ & 26 & - & $\begin{array}{l}\text { Left RLN } \\
\text { Paralysis }\end{array}$ & 1 & 3 \\
\hline 5 & $\begin{array}{l}\text { Midazolam }-2 \mathrm{mg} \\
\text { Fentanyl }-50 \mathrm{mcg}\end{array}$ & 40 & - & - & 1 & 2 \\
\hline 6 & $\begin{array}{l}\text { Midazolam }-2 \mathrm{mg} \\
\text { Pentazocine } 30 \mathrm{mg}\end{array}$ & 28 & - & - & 1 & 2 \\
\hline 7 & $\begin{array}{c}\text { Midazolam }-2 \mathrm{mg} \\
\text { Fentanyl }-50 \mathrm{mcg} \\
\text { Dextomedetomidine - } \\
20 \mathrm{mcg}\end{array}$ & 48 & - & $\begin{array}{c}\text { Naso- } \\
\text { pharyngeal } \\
\text { Airway }\end{array}$ & 1 & 2 \\
\hline 8 & $\begin{array}{c}\text { Midazolam - } 2 \mathrm{mg} \\
\text { Pentazocine } 30 \mathrm{mg} \\
\text { Dextomedetomidine - } \\
30 \mathrm{mcg}\end{array}$ & 40 & - & - & 1 & 3 \\
\hline 9 & $\begin{array}{c}\text { Midazolam }-2 \mathrm{mg} \\
\text { Pentazocine }-30 \mathrm{mg}\end{array}$ & 30 & - & - & - & 1 \\
\hline 10 & $\begin{array}{c}\text { Midazolam }-2 \mathrm{mg} \\
\text { Fentanyl }-50 \mathrm{mcg} \\
\text { Dextomedetomidine - } \\
30 \mathrm{mcg}\end{array}$ & 48 & - & - & 1 & 3 \\
\hline 11 & $\begin{array}{l}\text { Midazolam }-2 \mathrm{mg} \\
\text { Fentanyl }-50 \mathrm{mcg}\end{array}$ & 36 & - & - & 1 & 3 \\
\hline 12 & $\begin{array}{l}\text { Midazolam }-2 \mathrm{mg} \\
\text { Fentanyl }-50 \mathrm{mcg} \\
\text { Dextomedetomidine } \\
50 \mathrm{mcg}\end{array}$ & 40 & - & - & - & 2 \\
\hline \multicolumn{7}{|c|}{$. \mathrm{v} .=$ intravenous; RLN= Recurrent Laryngeal Nerve } \\
\hline
\end{tabular}

patient needs to be thoroughly evaluated during PAC. RA as stand-alone anesthesia is better to be avoided in patients with massive and fixed glands, retrosternal extension, anticipated difficult airway, and distorted anatomy due to the involvement of neck structures in carcinoma. In those cases, SCPB may be used as a part of multimodal analgesia along with GA.

Thyroidectomy under RA needs vigilant anesthesia monitoring, optimal analgosedation, and cooperation from the surgeon as well as from patients. The surgeon may have to contend with occasional patient movement, coughing, and swallowing. Direct application of pressure on the trachea or tracheal grooves using peanut gauze should be avoided. The patient needs to be counseled well about the sense of pulling and pressure on the surgical wound. A soft shoulder bolster is needed for patient positioning to avoid backache. Continuous monitoring of the airway with frequent adjustments of covering drapes may be needed.
Claustrophobic patients may not tolerate this approach. Awake surgery is better not attempted in case of retrosternal extension, higher grade malignancies, and extensive neck dissection.

SCPB may be associated with complications like intravascular injection into a vein or artery, LA systemic toxicity, hematoma formation, and infection like any other RA techniques. These complications can be easily avoided or minimized by appropriate technique and expertise.

\section{Conclusion}

Thyroidectomy under SCPB with MAC can be performed safely even in high-risk cases with favourable outcomes and without any serious complications. 
Declaration of patient consent: The authors certify that they have obtained all appropriate patient consent forms. In the form, the patient has given his consent for his images and other clinical information to be reported in the Journal. The patient understands that his name and initials will not be published, and due efforts will be made to conceal his identity, but anonymity cannot be guaranteed.

\section{Conflict of interest: Nil Source of support: None}

\section{References}

1. Malhotra S, Sodhi V. Anesthesia for thyroid and parathyroid surgery. Continuing Education in Anesthesia. Crit Care Pain. 2007; 7:55-8.

2. Motamed C, Merle J.C, Yakhou L et al. Intraoperative i.v. morphine reduces pain scores and length of stay in the post anaesthetic care unit after thyroidectomy. BrJ Anaesth. 2004; 93: 306-307.

3. U P S, KB P, Mohammed SJ, et al. Thyroidectomy Under Regional Anesthesia: An ORL Perspective.J Clin Diagn Res. 2015;9(10):MC01-MC4.

4. Khanna R, Singh DK. Cervical epidural anesthesia for thyroid surgery. Kathmandu Univ MedJ (KUMJ). 2009; 7(27):242-245.

5. Mukhopadhyay S, Niyogi M, Dutta M, et al. Bilateral superficial cervical plexus block with or without low-dose intravenous ketamine analgesia: effective, simple, safe, and cheap alternative to conventional general anesthesia for selected neck surgeries. Local Reg Anesth. 2012;5:1-7.

6. Singh S K. Improving safety and quality in regional anesthesia: An innovative app for Indian national regional anesthesia audit database, regional anesthesia database App. Journal of Anesthesia and Critical Care Case Reports May-Aug 2018; 4(2):4-6

7. Pandit JJ, Satya-Krishna R, Gration P. Superficial or deep cervical plexus block for carotid endarterectomy: a systematic review of complications. Br J Anaesth. 2007; 99:159-69.

8. Singh SK. The cervical plexus: Anatomy and ultrasound guided blocks. Anaesth Pain Intensive Care. 2015; 19:323-32.

9. Shih ML, Duh QY, Hsieh CB, et al. Bilateral superficial cervical plexus block combined with general anesthesia administered in thyroid operations. World J Surg. 2010;34:2338-2343.

10. Haugen TW, Andera LN, LaMadrid AB. Awake thyroidectomy. Laryngoscope. 2020;130(3):685-690.

\section{How to Cite this Article}

Kamat SV, Subramanian P, Eswaran K | Thyroid Surgeries Under Bilateral Superficial

Cervical Plexus Block - A Case Series | Journal of Anaesthesia and Critical Care Case

Reports | May-August 2021; 7(2): 17-20. 